\title{
Experiência estética e espaço potencial em net artes $^{1}$
}

\author{
Debora Faccion ${ }^{2}$
}

Resumo: A observação de eventos de net artes pode suscitar reflexões acerca dos processos de subjetivação, experiência estética e criatividade em ambientes virtuais na internet. Sob a hipótese de que a presença dos sujeitos nos ambientes virtuais transforma o paradigma estético, faz-se necessária a discussão teórica da forma como isso acontece e quais as suas consequências. Através da observação de dois eventos de net artes do artista Mark Amerika, pretende-se refletir sobre as possíveis consequências do uso dos dispositivos de comunicação que transportam os sujeitos para ambientes virtuais e as transformações das capacidades dos indivíduos em constante modulação.

Palavras-chave: experiência estética, evento, leitor, espaço potencial, ambiente virtual.

\begin{abstract}
The observation of net arts events can produce reflections concerning subjectivity processes, aesthetics experiences and creativity in virtual spaces of the internet. Considering the hypothesis that subjects present in virtual spaces can transform an aesthetic paradigm, it is necessary to theoretically discuss how this can happen and its consequences. Observing two net arts events from artist Mar Mark Amerika, this paper reflects on possible consequences of using a communication dispositive that transport subjects to virtual spaces, considering how subjects in constant modulation may have their capacities transformed.
\end{abstract}

Keywords: aesthetics experience, event, reader, potential space, virtual space. 
(...) I think we are actually making ourselves up as we go along and we are using language and performativity to create fictional identities. We are becoming what we were meant to become (AMERIKA, 2008).

Em entrevista disponibilizada no website do museu Tate Modern de Londres, Mark Amerika situa sua produção artística como uma forma de entender de que maneira os indivíduos se transformam e quem são eles quando se representam no espaço virtual. As questões apresentadas por Amerika partem da hipótese apresentada na citação que inicia este artigo, que considera parte da construção da identidade feita por meio da performance e da linguagem utilizadas nos ambientes virtuais interativos. Apesar de a questão da identidade parecer o problema final dessa hipótese, existem algumas questões que podem anteceder este pensamento, constituídas justamente pelo entendimento de como são formadas e apresentadas tais performances e linguagens. Esse entendimento será aqui buscado com o auxílio da análise ${ }^{3}$ de dois eventos de net artes criados por Mark Amerika: "Grammatron" (1996) e "Filmtext" (2002).

É importante notar que a hipótese deste artigo não coincide com a levantada por Amerika, mas sim, procura antecipar-se a ela. O estudo de eventos criados por um artista que possui como preocupação a construção das identidades nos ambientes virtuais traz a possibilidade de compreender algo anterior à formação de identidades, ou seja, de que forma são constituídos os diversos sentidos dentro do ambiente virtual. Desta forma, este artigo possui como hipótese a transformação do paradigma estético nos ambientes virtuais da internet e buscará apresentar alguns caminhos críticos para o entendimento das novas configurações que podem ser iniciadas a partir dessa transformação, dentre as quais se encontra a construção de diferentes identidades.

Neste artigo, inicialmente, serão apresentados alguns termos necessários para o melhor desenvolvimento do tema, bem como algumas contextualizações importantes para situar a produção artística de Mark Amerika. Em continuidade, será feita uma descrição dos eventos selecionados, com a finalidade de apresentálos ao leitor. Após esses dois momentos, será apresentado um estudo acerca 
das questões do processo e da estética, que pode ser feito por meio dos eventos observados e, por fim, será desenvolvida uma reflexão acerca das perspectivas e perguntas possíveis de serem retiradas deste estudo.

\section{Contexto e termos}

Grammatron e Filmtext são duas novelas criadas por Amerika para a internet, classificadas pelo próprio artista como "internet art". Tal termo foi desenvolvido e, com a finalidade de melhor compreender a diversidade de influências e configurações das produções de Mark Amerika, neste artigo, foi feita a opção pela utilização do termo "net artes", proposto por Fernanda Duarte:

\footnotetext{
'Net' por abarcar outras redes e associações para além da world wide web, e 'artes', no plural, para caracterizar um espaço de pesquisa aberto, não formado por objetos pré-concebidos e disposto a reinventarse. Prezamos, dessa forma, por um olhar disposto a acolher as potencialidades do fazer artístico (DUARTE, 2007, p. 20).
}

A produção de net artes é própria da contemporaneidade, uma vez que depende de dispositivos recentemente criados e ainda em desenvolvimento. Entretanto, assim como os dispositivos dos quais utiliza, net artes podem (e talvez precisem) também ser entendidas como um desdobramento de revoluções iniciadas na década de 1960 (ARANTES, 2005). A relação intrínseca entre as tecnologias de mídia e tais produções artísticas permitiu a criação de uma nova vertente, chamada de artemídia. A situação da artemídia dentro de um contexto histórico pode propiciar a compreensão do início de um pensamento que prioriza o processo de criação, pois na década de 60 diversos artistas desenvolveram suas obras em performance ou convidaram o público para participar de suas criações.

Transportada para o ambiente digital, a questão de processo das obras é traduzida na interatividade e fica ainda mais evidente, uma vez que a obra acontece somente quando acessada por alguém, ou seja, ela não está terminada e permanece aberta para as diversas influências trazidas pelos seus 
leitores (ECO, 1976). Essas reflexões acerca do processo e do acontecimento de net artes criam a necessidade de utilização do termo "evento de arte", ao invés de "obra de arte", pois deixam claro que essas produções artísticas não são obras acabadas, e sim eventuais.

É também necessária uma reflexão acerca do termo utilizado para denominar o público que entra em contato com net artes aqui estudadas. De fato, na maioria das situações, denominar aquele que entra em contato com eventos de net artes de "público" pode não ser correto, uma vez que a internet permite também um contato privativo com net artes (BROGGER, 2000). Além disso, os termos mais usuais como "interator" e "navegador" podem ser considerados limitados para este estudo, pois determinam formas especificas de se relacionar com tais eventos, interagindo ou navegando. Desta forma, faz-se aqui a opção por denominar aqueles que entram em contato com Grammatron e Filmtext de "leitores", pela semelhança encontrada entre a forma de se relacionar com estes eventos e o processo descrito por Wolfgang Iser para a leitura de textos:

\footnotetext{
Em relação ao objeto da percepção, sempre nos encontramos diante dele, ao passo que, no tocante ao texto, estamos dentro deste. É por isso que a afeição entre texto e leitor se baseia num modo de apreensão diferente do processo perceptivo. Em vez da relação sujeito-objeto, o leitor, enquanto ponto perspectivístico, se move por meio do campo de seu objeto. A apreensão de objetos estéticos tecidos por textos ficcionais tem sua peculiaridade em sermos pontos de vista movendo-nos por dentro do que devemos apreender (ISER, 1999, p. 12).
}

$\mathrm{O}$ ato de leitura descrito por Iser é feito em três momentos, que podem ser relacionados com o processo cognitivo proposto na semiótica. Segundo Iser, o leitor é um ponto de vista dentro de um texto e, para manter-se em movimento, é preciso que a leitura desperte expectativas. Essas expectativas requisitarão a memória do leitor para a associação com signos já conhecidos por ele, que, por fim, poderá desenvolver seus próprios significantes (PEIRCE, CP 2.228).

Algumas questões aqui levantadas acerca da terminologia escolhida pressupõem um tipo único de experiência, criado na relação entre leitor e 
evento. As potencialidades de acontecimento desse tipo de experiência e as consequências de sua realização ou não serão mais bem abordados após a descrição de Grammatron e Filmtext, pois são parte da dificuldade do estudo dos ambientes virtuais na internet como iniciadores de um processo de significação.

\section{Descrição dos eventos}

\section{Filmtext}

Filmtext possui uma interface em um primeiro momento semelhante às dos jogos eletrônicos. É estruturado em oito fases independentes entre si (podem ser acessadas de acordo com a vontade do leitor) e divididas em duas partes (Transition 1 e 2). Possui como pano de fundo imagens desérticas, que colocam o leitor em um tempo desconhecido, porém, provavelmente situado no futuro. Alguns pontos das imagens de fundo podem ser clicados, bem como alguns caracteres distribuídos na tela.

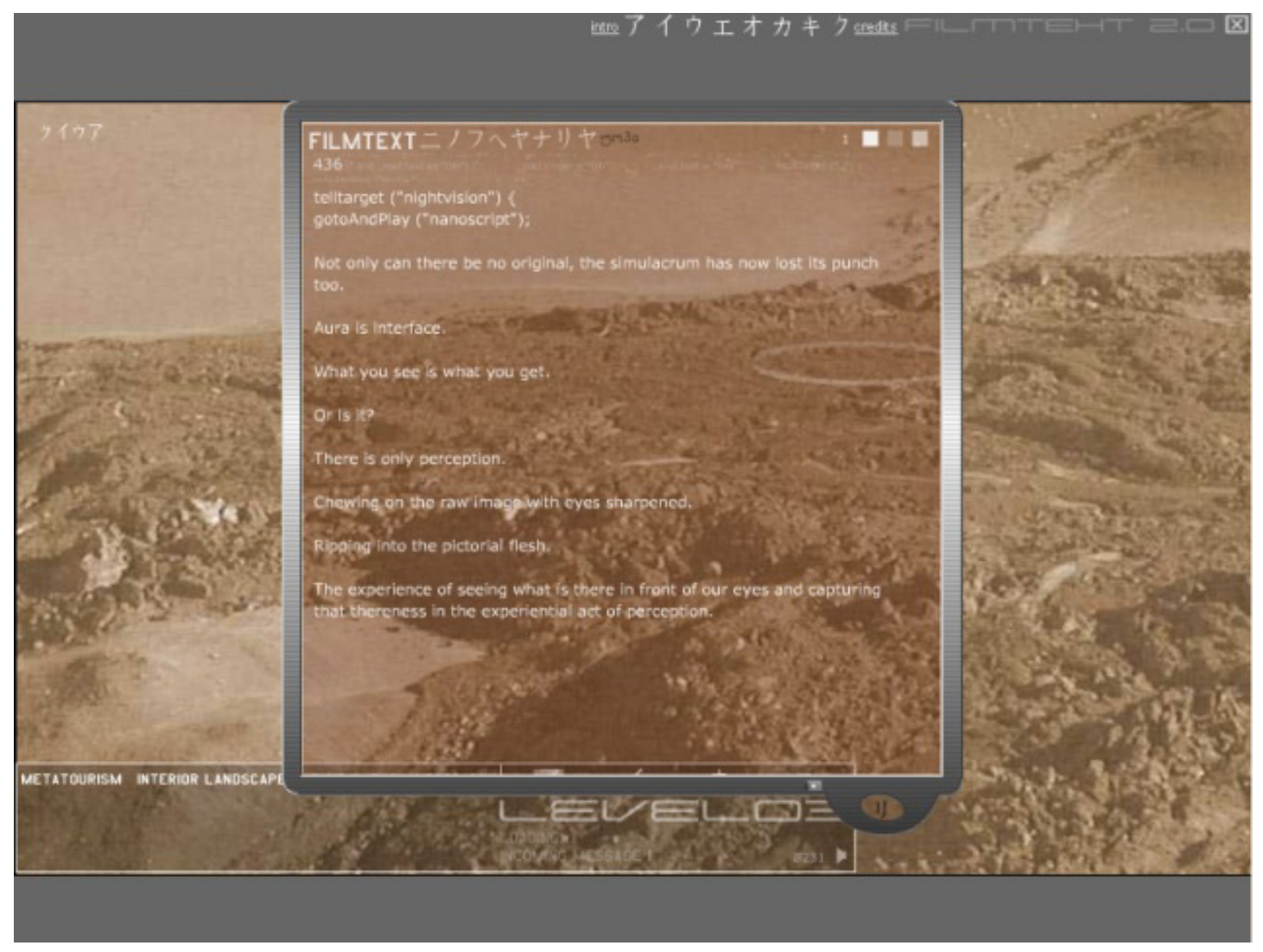


Determinados cliques fazem surgir pequenas caixas, que apresentam três textos ou três vídeos, que podem ser interrompidos pelo leitor. Os textos dessas caixas são iniciados com códigos semelhantes ao do sistema MS DOS e possuem frases soltas, que tratam de temas diversos, como linguagem, realidade, sensações etc. Os vídeos, por sua vez, possuem imagens rápidas e confusas; algumas difíceis de serem reconhecidas e outras com objetos que parecem aleatórios, como uma janela e um trem. Existem ainda textos que surgem fora de caixas, que, assim como os primeiros, apresentam frases soltas sem temática específica. Tem-se, ainda, o texto de autorização para as próximas fases, que aparece após o primeiro clique em cada uma delas, e que, numa observação geral, não possui utilidade, por ser possível acessar todas as fases por meio dos caracteres localizados no canto direito superior da tela. O primeiro desafio aparente é o de decifrar o que seria necessário para ter acesso às fases posteriores, e esse provavelmente é o maior jogo dentro do jogo de significados proposto em Filmtext: não é preciso fazer nada para chegar ao fim.

Apesar de não existir uma narrativa estruturada, é possível imprimir uma linearidade ao evento, com início, clímax e fim. Na primeira fase, um dos vídeos contém a imagem da sombra, em um chão pedregoso, de um homem com chapéu (que pode ser entendido como personagem-narrador). Esta mesma imagem aparece em um vídeo na sétima fase de Filmtext, na tela principal na oitava fase e na caixa de som que se abre em todas as fases, da qual são emitidos sons de uma voz masculina, com algumas frases que podem ser entendidas e outras não. 


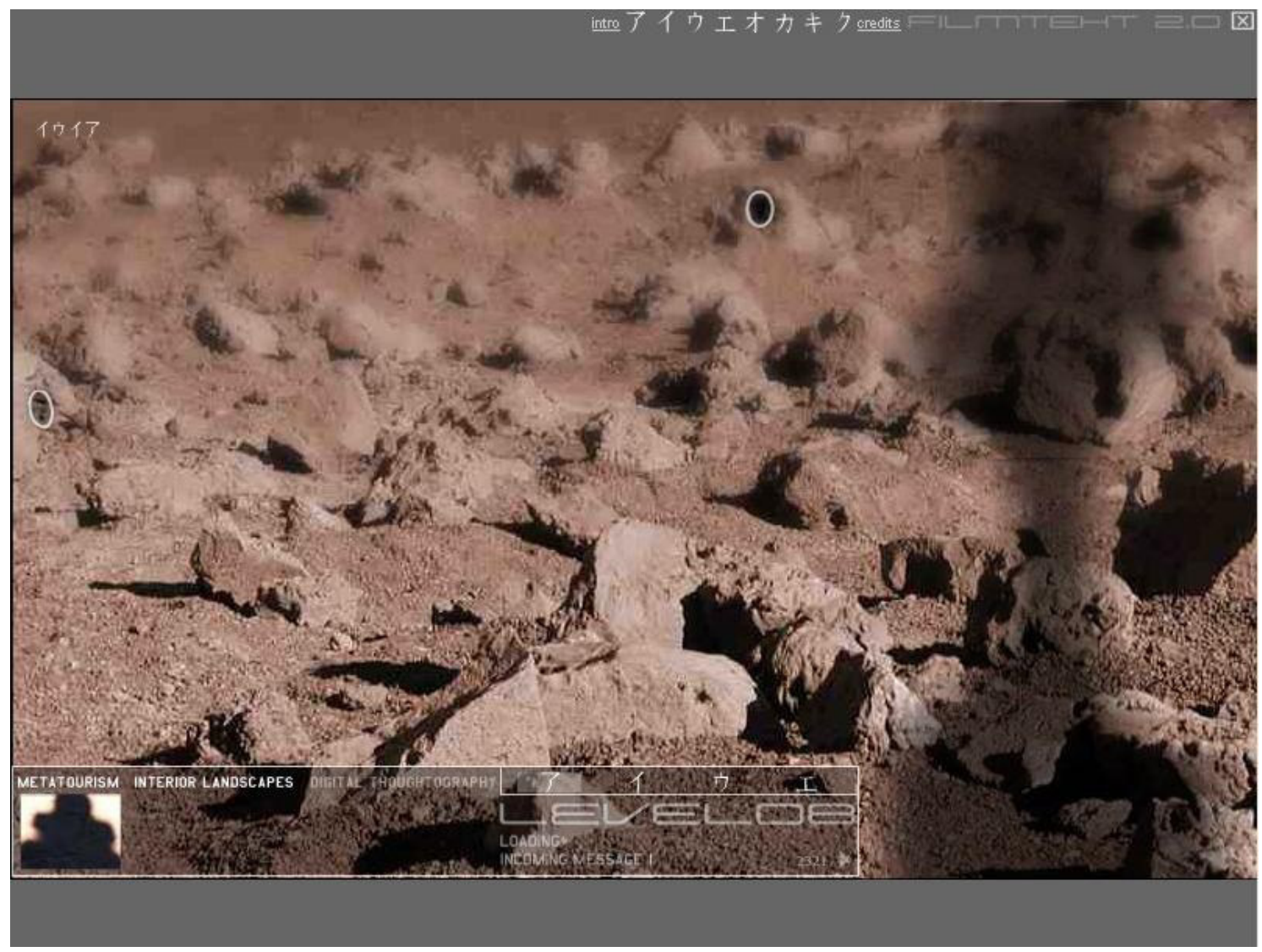

Personagem-narrador

O clímax da narrativa acontece na sexta fase, antes da segunda parte da obra. Esta é a fase que mais se diferencia das outras anteriores, pois somente nela tem-se uma imagem de um objeto que pode ser identificado (talvez um telescópio) do qual sai o texto em um formato diferente dos outros. Além disso, o clímax pode ser sentido pelo som forte que toca ao fundo: um canto de vozes femininas, que parece um lamento. 


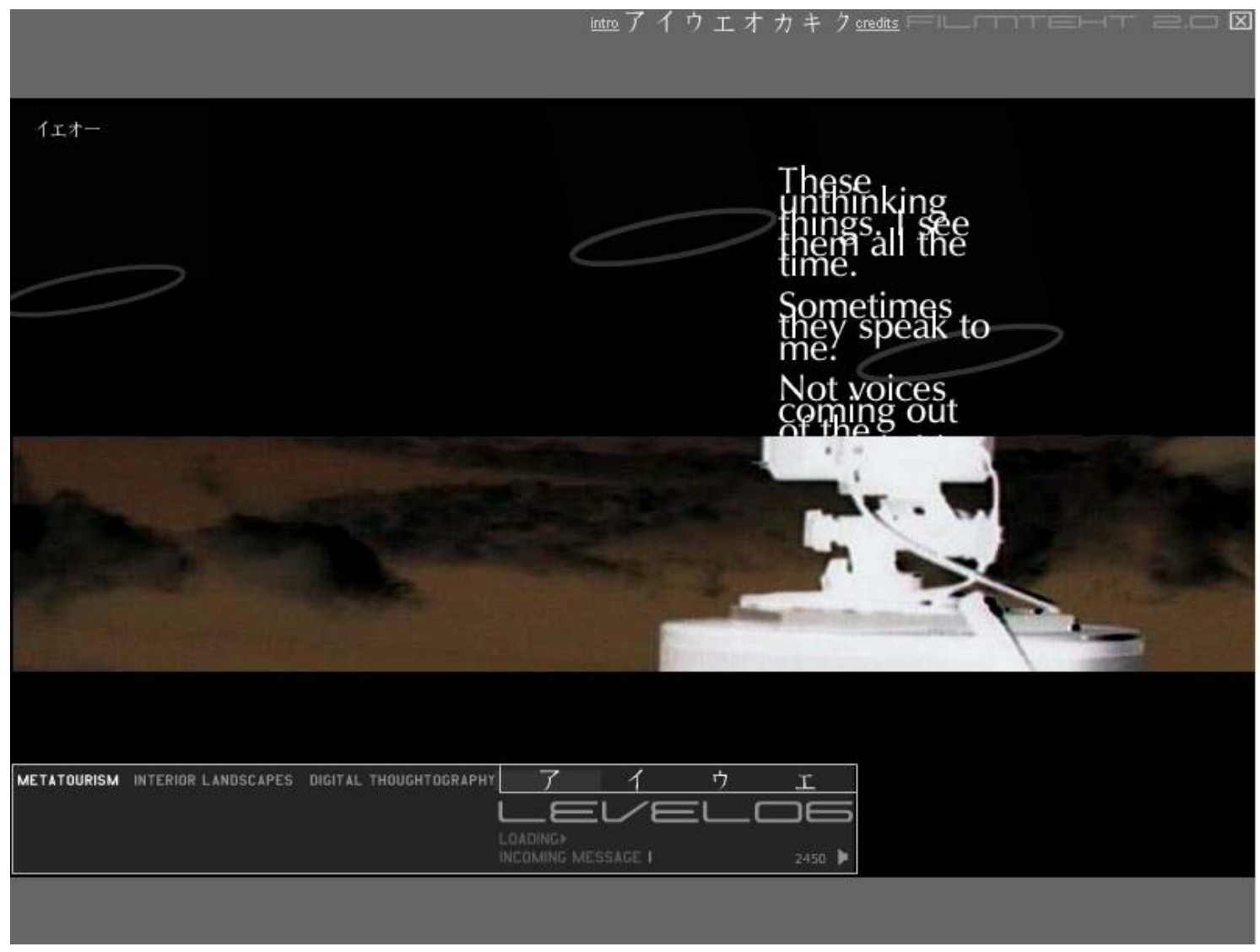

Sexta fase

A confusão de referências e informações transmite uma idéia geral de uma situação e de um possível sentimento. Situado dentro do contexto criado em Filmtext, o leitor pode sentir-se impelido a decifrar o evento e compreender o sentimento do personagem-narrador. Entretanto, continua com a dúvida criada por participar de um jogo sem vencedores, uma narrativa sem fim, textos sem significado e vídeos de imagens indecifráveis. Por outro lado, ao mesmo tempo em que Filmtext se apresenta como uma incógnita, todas as suas referências parecem conhecidas, ou reconhecíveis apesar de incertas, o que pode criar no leitor o desconforto e a expectativa necessários para manter o seu ponto de vista em movimento. 


\section{Grammatron}

Grammatron pode ser considerado uma proposta de uma nova forma de apresentação de um livro no ambiente virtual. O evento começa com um texto introdutório, chamado Interfacing, apresentado em pequenos trechos em várias páginas, sobre um fundo vermelho. Este texto introdutório não convida o leitor a encontrar sentido ou linearidade, uma vez que ele é rápido e sua leitura é feita dentro do tempo do programa. Em algumas páginas aparecem pequenas imagens animadas de forma simples, que não parecem ilustrar o texto escrito acima delas. Tais imagens talvez cumpram o papel de acentuar o estranhamento ao texto escrito, mas, em alguns momentos, elas retomam o interesse do leitor ao evento, pois se tornam os únicos elementos passíveis de compreensão para ele.

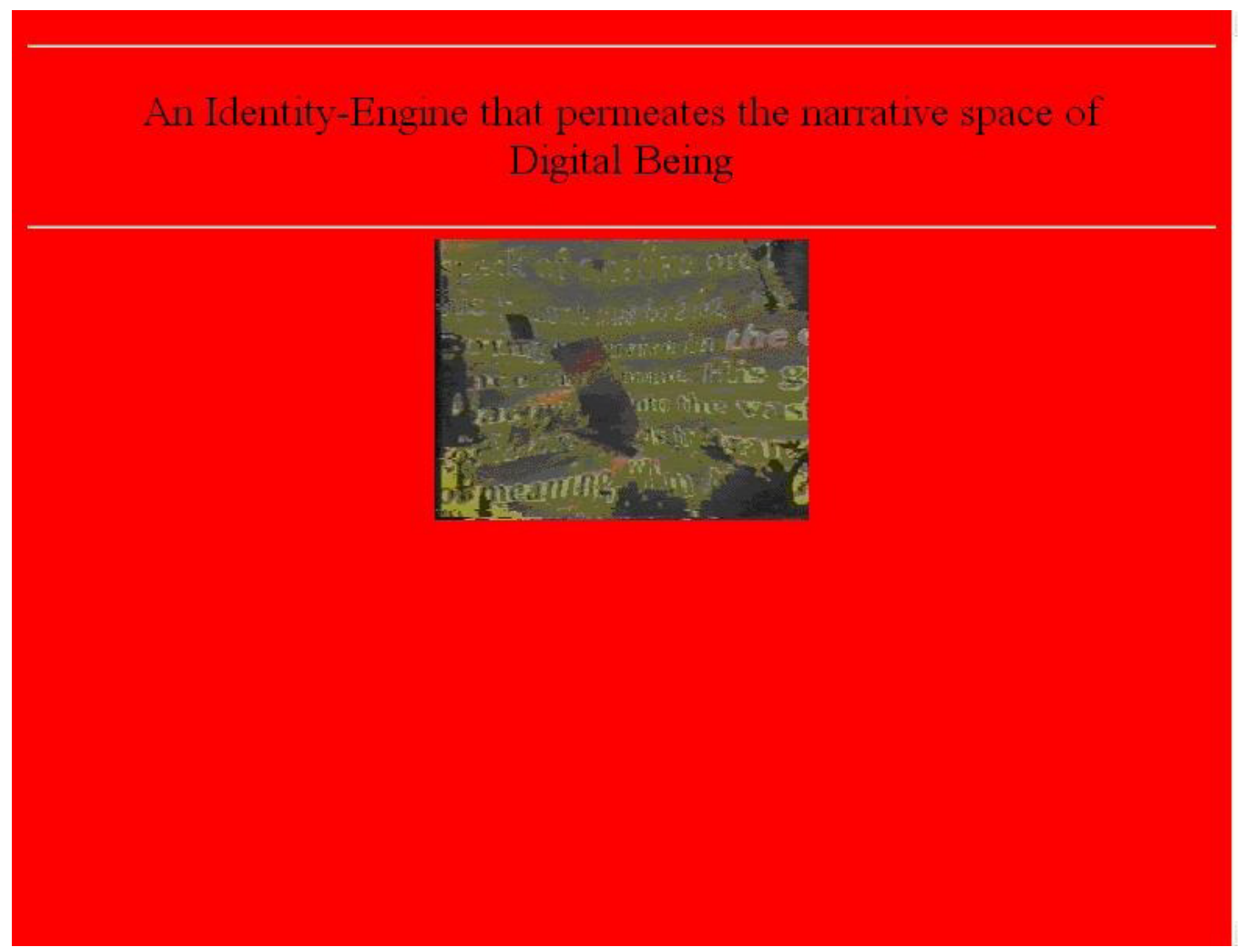

Interfacing 
Depois da introdução, é iniciada uma segunda parte de Grammatron, na qual o texto continua a ser desenvolvido em trechos, mas a cada um deles o leitor possui como opção de um a três links que determinam diferentes caminhos para a narrativa. A narrativa formada é difícil de ser compreendida, pois é recortada e não possui linearidade de acontecimentos. Além disso, o autor utiliza de vários neologismos, que deixam espaço para diferentes interpretações. A partir da dificuldade em compreender o texto, é possível questionar se o objetivo principal do leitor deveria, de fato, ser a busca de sentido na obra. Porem, uma vez que Grammatron é constituído somente por texto (com exceção das pequenas imagens citadas anteriormente), o próprio texto é o evento e, portanto, ele deveria transmitir alguma mensagem. Por outro lado, é sabido que o nãosentido pode também conter uma mensagem, o que pode requisitar do leitor uma posição ativa dentro do evento.

\footnotetext{
Abe Golam

Abe Golam, legendary info-shaman, cracker of the sorcerer-code and creator of Grammatron and Nanoscript, sat behind his computer, every speck of creative ore long since excavated from his burnt-out brain, wondering how he was going to survive in the electrosphere he had once called home. His glazed donut eyes were spacing out into the vast electric desert looking for more words to transcribe his personal loss of meaning. "I'm Abe Golam, an old man. I drove a sign to the end of the road and then I got lost. Find me."
}

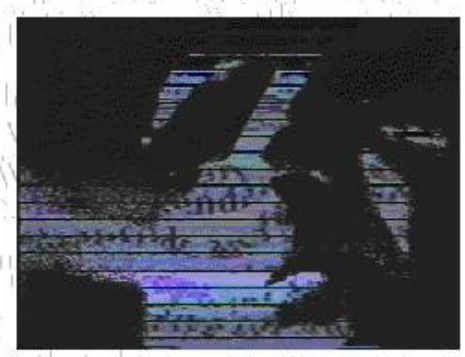


A narrativa de Grammatron é traçada em torno dos questionamentos de vida feitos por um personagem principal, chamado de Abe Golam e identificado como um mágico criador de softwares, um artista do século XXI, um "infoshaman". Abe Golam está à procura de um sentido para sua existência dentro da "eletrosfera", ambiente virtual apresentado pelo texto. Entretanto, não é possível identificar que tipo de ser é Abe Golam nem do que é constituída a eletrosfera, uma vez que ela parece mais complexa que o ambiente virtual da internet. Além disso, as referências intertextuais que permeiam o texto não são evidentes, apesar de, assim como em Filmtext, existir a sensação de se estar em um território conhecido.

É preciso em torno de 3 horas para chegar ao fim de Grammatron. A quantidade de links apresentada é grande e o texto se repete, a depender dos links clicados. Por isso, parece impossível percorrer um mesmo caminho em Grammatron mais de uma vez e, ao chegar ao fim, o programa é reiniciado desde a Interfacing. Existe ainda quatro opções de som apresentados aos leitores separados do texto. São músicas que variam entre falas e sons barulhentos. Uma delas possui a voz de uma mulher dando instruções como em uma música para meditação, com frases como "Encontre-se, caminhe dentro de si mesmo". Outra música apresenta uma voz metalizada e outra começa com um homem cantarolando o hino dos EUA e termina com uma breve história. Por fim, existe uma música somente instrumental, que começa tranquila e adquire um tom de mistério. Todas essas músicas podem ajudar a situar o leitor para a criação de um ambiente no qual ele acesse a sensação que Grammatron tem a transmitir.

\section{Processo e estética}

A relação entre evento e leitor, bem como qualquer atividade feita em um ambiente virtual na internet, é possibilitada por uma interface. No caso dos eventos aqui analisados, é possível entender as interfaces como dicionários, pois possuem o papel de organizadoras de significados (PINTO, 2008). As 
interfaces padronizam de modo linear certas funções e ações comuns a todos os leitores. A necessidade da interface impõe uma série de características a net artes, uma vez que ao mesmo tempo em que evidencia os caminhos abertos pelo artista para a interatividade, limitam a ação dos leitores dentro de um padrão pré-estabelecido. Dessa forma, a interface pode ser entendida, por um lado, como um facilitador, à medida que apresenta signos que não precisam ser interpretados pelos leitores, e, por outro lado, um ponto de dificuldade no que diz respeito ao aspecto estético que as net artes podem desenvolver, pois cria uma tendência constante à terceiridade.

Pierre Levy explica da seguinte forma a função das interfaces:

Interface é uma superfície de contato, de tradução, de articulação entre dois espaços, duas espécies, duas ordens de realidades diferentes: de um código para o outro, do análogo para o digital, do mecânico para o humano... Tudo aquilo que é tradução, transformação, passagem, é da ordem da interface (LEVY, 1998, p. 181).

A partir da definição dada por Levy é possível encontrar um aspecto fundamental de comunicação em net artes, em consequência do caráter indispensável das interfaces para os ambientes virtuais na internet. Este aspecto de comunicação está no fato de que existe algo que precisa ser comunicado (regras a serem seguidas e situações a serem explicadas) em net artes, o que se encontra anterior e permeará toda a ação do leitor nos eventos. É possível entender que, por esse motivo, existe uma determinação do dispositivo que limita em parte o caráter artístico dos eventos de net artes e, consequentemente, influencia a experiência do leitor.

Nos eventos de net artes de Mark Amerika aqui apresentados as limitações impostas pelas interfaces podem ser facilmente notadas. As necessidades de situar o leitor dentro de um ambiente até então desconhecido e de estabelecer formas de contato entre leitor e evento fazem com que o processo de construção da presença do leitor dentro desses eventos limite-se somente aos cliques e à consequente visualização de efeitos e informações. 
Ou seja, a interatividade possibilitada pela interface parece não dar conta da interação que todo leitor possui em potencial.

A diferenciação entre interatividade e interação parece então necessária e pode ser entendida a partir da explicação de Leonardo Forny:

O conceito de interação vem da física e refere-se ao comportamento de partículas cujo movimento é alterado pelo movimento de outras partículas. A partir daí este conceito passou pela psicologia e sociologia, onde a premissa é que nenhuma ação humana ou social existe separada da interação. Então, somente depois o termo foi incorporado ao campo da informática e transmutado em interatividade. Para, ainda nos anos 70, designar a transição da máquina computacional rígida para uma máquina conversacional (FORNY, 2006, p.3).

Ou seja, a interação diz respeito ao universo de entendimentos criado pelo leitor em sua relação com o evento, enquanto a interatividade trata das possibilidades de ação de fato sobre o evento, apresentadas pela interface ao leitor. Desta forma, embora a interatividade possa engrandecer a interação, esta última dependeria muito mais da disposição e da capacidade do próprio leitor em desenvolver seus pontos de relação com o evento.

Entretanto, é preciso ponderar sobre as experiências propiciadas pelos eventos para a criação de tais pontos de relação por parte do leitor. Em Grammatron, por exemplo, a novidade da experiência proporcionada pelo evento encontra-se muito mais na apresentação diferenciada de um texto que na interatividade ou interação. É possível questionar a capacidade de Grammatron em propiciar o desenvolvimento das capacidades de criação, elucidação, imaginação etc. de seus leitores, uma vez que se trata de um evento que requisita uma postura demasiada ativa por parte do leitor para decifrar os significados do texto apresentado e minimamente ativa no que tange à sua possibilidade de ação efetiva dentro do evento. O tipo de relação criado nesse caso pode ser entendido como rotineiro, pois estabelece apenas parâmetros de comunicação entre as partes envolvidas. 
A comunicação, ainda que possua como intenção um entendimento entre as partes, pode ser feita sem que exista como consequência final o desenvolvimento de uma relação única, ou seja, pode ser feita sem que aconteça a integração das capacidades humanas, que caracteriza uma experiência estética (GUIMARÃES; LEAL, 2008). A experiência estética possui em si um aspecto de primeiridade, pois, a partir de um contato único e efêmero é desenvolvida uma igualmente única consciência. Esse tipo de experiência pode disponibilizar aspectos singulares dos indivíduos e permitir a criação de interpretantes inéditos.

É importante notar que o ineditismo aqui discutido não diz respeito ao todo social, mas sim aos seres individualmente. Tal observação é fundamental, pois é sabido que tanto a arte quanto a comunicação dependem da intertextualidade e da hipertextualidade para possibilitar o acesso e o entendimento dos indivíduos aos conteúdos dos eventos. Dessa forma, pode-se considerar que, apesar de todo discurso possuir "milhares de fios dialógicos" (KRISTEVA, 1974, p. 64) e várias referências ou links externos, existe algo específico e circunstancial que pode surgir devido ao espaço potencial (WINNICOTT, 1975) criado pela experiência estética tida pelo leitor.

Winnicott desenvolveu o conceito de "espaço potencial" para explicar o processo de criatividade das crianças durante o ato de brincar. Segundo Winnicott, existe um espaço de relação entre a realidade e a imaginação, no qual, através de um jogo de ilusão, a criação acontece. A noção de espaço potencial (aqui expandida para todas as fases de vida do ser humano, não só a infância) pode ajudar a entender a possível dificuldade imposta pela virtualidade dos ambientes da internet para a experiência estética.

O espaço potencial pode ser entendido como o espaço no qual acontece a relação entre a coisa e o signo, ou ainda o ir e vir entre real e virtual. Ou seja, é parte do caminho traçado pelos sujeitos durante um processo de subjetivação. Enquanto o evento está em um ambiente virtual e se encontra com a realidade através de sua relação com o leitor, este, por sua vez, é constituído no ambiente 
real, mas relaciona-se com os eventos por meio de sua própria virtualidade, ou seja, seu universo imaginativo e criativo.

Segundo Jorge Coli (2005), "a arte é o que impõe uma ficção como realidade". Em net artes de Mark Amerika, a imposição do real pode ser vista como resultado da estruturação dos próprios programas que as constituem. Entretanto, tal imposição do real não acontece a partir de uma ficção, mas sim, procura criar uma ficção posterior, apresentada na simulação das imagens sintéticas. Assim, paradoxalmente ao ambiente virtual no qual são inseridas, as net artes surgem de um esforço de realidade, de enquadramento, de encaixe de diversas intersubjetividades às quais os sujeitos já foram submetidos. O esforço de realidade criará, portanto, uma ficção, que deverá continuar ficcional.

É possível questionar a capacidade de net artes para garantir o ir e vir entre real e virtual próprio da arte, ou seja, as flutuações entre o que as coisas nos apresentam de fato e o que percebemos delas em nossos processos de subjetivação. E tal questionamento pode ser transportado para vários outros processos de relação criados dentro dos ambientes virtuais na internet, sobretudo aqueles nos quais os sujeitos são, assim como em net artes, convidados a se expressar e a modular suas presenças de acordo com os ambientes apresentados.

\section{Conclusão}

A reflexão aqui feita, longe de possibilitar uma conclusão, tende a levantar outros questionamentos acerca das potencialidades de transformação dos sujeitos nos ambientes virtuais na internet, a partir de suas experiências e capacidades de subjetivação. Uma vez que a interatividade possibilitada pelo dispositivo computacional hoje largamente utilizado limita-se ainda aos recursos que requisitam somente os sentidos de visão e audição dos leitores, a estética relacionada com os eventos na internet precisa, logo de início, ser considerada diferente daquela até então experimentada. 
A mudança do paradigma estético nos ambientes virtuais da internet pode ser entendida pelo fato de que o espaço potencial construído nas relações entre leitores e eventos na internet não possui como um de seus fatores um elemento de realidade, apenas signos, representações ou simulações. Desta forma, talvez seja necessário considerar a existência de outro tipo de espaço potencial, formado a partir da relação entre imagem e imaginação, mas ainda capaz de estimular a criatividade. Percebe-se aqui a intenção de entender a possibilidade de acesso a outro tipo de subjetivação, que não surge a partir da significação sobre a realidade, mas sim, da significação sobre a significação, o que talvez possa ser entendido como um engrandecimento das capacidades humanas trazido pela utilização das máquinas. Como defende Guattari, "não tem sentido o homem querer desviar-se das máquinas já que, afinal de contas, elas não são nada mais do que formas hiperdesenvolvidas e hiperconcentradas de certos aspectos de sua própria subjetividade" (GUATTARI, 1999, p. 177).

A partir de net artes de Mark Amerika aqui utilizadas como objeto empírico, parece difícil imprimir de fato tal potencial de transformação e engrandecimento das capacidades humanas aos eventos na internet, pois a apresentação desses eventos não parece capaz de despertar um interesse suficiente nos leitores para uma interação que permita uma experiência estética, a formação de um espaço potencial e a consequente criação de algo novo, um interpretante.

É possível perceber que a presença nos ambientes virtuais na internet cria em teoria uma possibilidade de transformação, pois requisitaria presenças diversas dos sujeitos, moduladas de acordo com as especificidades de cada ambiente. Por outro lado, é possível questionar até que ponto essa presença é de fato convidada e permitida e, de que maneira ela poderia transformar os processos de subjetivação e conscientização dos sujeitos. Por esses motivos, o uso da internet precisa ainda ser observado atentamente, principalmente no que diz respeito ao seu uso pelos jovens, uma vez que o incentivo ao desenvolvimento das capacidades de imaginação e subjetivação é fundamental para a formação de adultos conscientes. 


\section{Referências}

ALMEIDA, M.V.; FACCION, D.; FRAGOSO, A.; MACIEL, D.. Produção e recepção de net artes: um estudo de intertextualidade e interatividade [Projeto experimental Graduação em Comunicação Social]. Belo Horizonte: Pontifícia Universidade Católica de Minas Gerais, 2008.

AMERIKA, M. Filmtext. Disponível em: <www.markamerika.com/filmtext> [Acessado em março de 2010].

AMERIKA, M. Grammatron. Disponível em: <www.grammatron.com> [Acessado em março de 2010].

AMERIKA, M. Intermedia Art. Entrevista em vídeo, 2008. Disponível em: <www.tate. org.uk/intermediaart/mark_amerika.shtm> [Acessado em março de 2010].

ARANTES, P. Arte e mídia: perspectivas da estética digital. São Paulo: SENAC, 2005.

BROGGER, A. "Net art, web art, online art, net.art?" ON OFF Magazine. Dinamarca, 2000. Disponível em: <www.hvedekorn.dk> [Acessado em março de 2010].

COLI, Jorge. "O invisível das imagens". In: NOVAES, A. (Org.). Muito além do espetáculo. São Paulo: Senac São Paulo, 2005. v. 01. P. 80-93.

DUARTE, F. A materialidade dos dispositivos na construção de experiências em net artes [Dissertação de Mestrado em Comunicação]. Belo Horizonte: Universidade Federal de Minas Gerais, 2007.

ECO, U. Obra aberta: forma e indeterminação nas poéticas contemporâneas. Trad. Giovanni Cutolo. São Paulo: Perspectiva, 1976.

FORNY, L. "Arte e Interação: Nos Caminhos da Arte Interativa?" Revista virtual n.53, outubro/novembro 2006.

GUATTARI, F. "Da produção de Subjetividade". In: PARENTE, A. (Org.). Imagem máquina: A era das tecnologias do virtual. Rio de Janeiro: Editora 34, 1999.

GUIMARÃES, C.G.; LEAL, B. "Experiência Estética e Experiência Mediada". InTexto, 2008, v.2, p.1-12.

ISER, W. O ato da leitura: uma teoria do efeito estético. São Paulo: Editora 34, 1996. 
KRISTEVA, J. Introdução à semanalise. São Paulo: Perspectiva, 1974.

LÉVY, P. As Tecnologias da Inteligência. Rio de Janeiro: Editora 34, 1998.

PEIRCE, C.S. Collected Papers. 8 vols. Cambridge: Harvard University Press, 19311958.

PINTO, J. "Sinopse parcial de um trabalho sobre como podemos fazer ciência hoje". Revista Matrizes, 2008, V. 2, p.177-184.

WINNICOTT, D.W. O Brincar e a Realidade. Rio de Janeiro: Imago, 1975.

1 Este artigo foi apresentado no Intercom Sudeste - XV Congresso de Ciências da Comunicação na Região Sudeste, em Vitória-ES, de 13 a 15 de maio de 2010.

2 Mestranda do Curso de Comunicação Social da FACOM-UFJF. Email: dfaccion@gmail.com.

3 A análise aqui apresentada foi iniciada no Projeto Experimental, trabalho de monografia apresentado como pré-requisito para a formação em Comunicação Social na Pontifícia Universidade Católica de Minas Gerais, feito em conjunto pelos alunos Antonio Fragoso, Daniel Maciel, Debora Faccion e Marcus Vinicius de Almeida, sob a orientação do Prof. Dr. Julio Pinto. 